Article

\title{
Entrepreneurship Education in a Multidisciplinary Environment: Evidence from an Entrepreneurship Programme Held in Turin
}

\author{
Eleonora Fiore $^{1,+}$, Giuliano Sansone ${ }^{2, *,+}+$ (i) and Emilio Paolucci ${ }^{2}$ \\ 1 Department of Architecture and Design, Politecnico di Torino, 10129 Turin, Italy; eleonora.fiore@polito.it \\ 2 Department of Management and Production Engineering, and Entrepreneurship and Innovation Center, \\ Politecnico di Torino, 10129 Turin, Italy; emilio.paolucci@polito.it \\ * Correspondence: giuliano.sansone@polito.it; Tel.: +39-347-189-4988 \\ + These authors contributed equally to this work.
}

Received: 28 February 2019; Accepted: 24 March 2019; Published: 26 March 2019

\begin{abstract}
Entrepreneurship education can increase student's entrepreneurial skills and intention; and entrepreneurship activities stimulate economic growth. Therefore, the number of entrepreneurship courses is increasing, but they are often offered to students from a specific field of study and/or to only one educational level, even though multidisciplinarity is important for entrepreneurship. This study has carried out an exploratory single case study on an entrepreneurial programme in a multidisciplinary environment, that is, the Contamination Lab of Turin (CLabTo). Moreover, pre- and post-surveys have also been conducted in order to perform some qualitative analyses. The results show the importance of creating teams with different competencies, cognitive and decision-making skills. Moreover, we explain how design-thinking is useful in entrepreneurship education and that a challenge-based entrepreneurship course leads to cooperation with external actors in the local entrepreneurial ecosystem. It is also explained what the obstacles and opportunities of these programmes are and how to improve them. Moreover, on the basis of pre- and post-surveys, our qualitative analyses show that the students' overall perception of their abilities to work in a multidisciplinary team, their entrepreneurial skills and entrepreneurial intentions increased slightly. In short, this work is aimed at increasing the importance of entrepreneurship education in a multidisciplinary environment and the use of practical-oriented teaching models.
\end{abstract}

Keywords: entrepreneurship education; multidisciplinarity; entrepreneurial skills; entrepreneurial intention; design thinking

\section{Introduction}

Universities currently have the aim of encouraging economic and social development, in part through entrepreneurship education (Souitaris et al. 2007; Wilson et al. 2007; O'Connor 2013; Rauch and Hulsink 2015; Siegel and Wright 2015; Barba-Sánchez and Atienza-Sahuquillo 2018), since it is capable of stimulating the entrepreneurial skills of students (Peterman and Kennedy 2003; Wilson et al. 2007; Athayde 2009; Morris et al. 2013; Sánchez 2013) and their Entrepreneurial Intention (Peterman and Kennedy 2003; Souitaris et al. 2007; Athayde 2009; Sánchez 2011, 2013; Martin et al. 2013; Walter et al. 2013; Bae et al. 2014; Zhang et al. 2014; Gielnik et al. 2015). In fact, the number of entrepreneurship courses is increasing all over the world (Katz 2003; Kuratko 2005; Solomon 2007; Katz 2008; Fretschner and Weber 2013; Torrance et al. 2013). Policymakers are promoting entrepreneurship education (Gibb 2011; O'Connor 2013; Hoppe 2016) in part because the European Commission included the "sense of initiative and entrepreneurship" as one of the eight 
key competencies that all individuals need for personal fulfilment, social inclusion and employment in our economy (EC European Commission 2006). For instance, in 2016 the Italian Ministry of Education, University and Research (MIUR) funded the creation of "Contamination Labs" in Italy to foster entrepreneurial and innovative abilities in students from different fields of study and with different educational levels. Even though many studies have been conducted on entrepreneurship education (see, for example, the recent literature review by Nabi et al. 2017), they usually refer to a single specific field of study, such as business and management (DeTienne and Chandler 2004; Musteen et al. 2018), sciences and technology (Souitaris et al. 2007; Barba-Sánchez and Atienza-Sahuquillo 2018) or computer engineering (Arias et al. 2018), although there are a few exceptions, such as the study by Thursby et al. (2009). However, Thursby et al. (2009) analysed an entrepreneurship programme that was only offered to specific education levels for engineering, law and business students. In fact, most of the aforementioned studies, such as the studies carried out by Arias et al. (2018) and Barba-Sánchez and Atienza-Sahuquillo (2018), are focused on entrepreneurship education for a specific level of education (generally either undergraduate or graduate students). This could be due to the fact that introducing a new entrepreneurship course to students who come from different fields of study and with different educational levels can be complex, although this depends on the university policies. How entrepreneurship should be taught in a multidisciplinary environment (Rauch and Hulsink 2015). Teaching entrepreneurship to students from different fields of study and with different levels of education may be more challenging than teaching students from the same field of study and with the same level of education. Moreover, the impact of entrepreneurship education on a student's entrepreneurial skills and EI might vary considerably, depending on the student's characteristics, including their field of study and educational level (Fayolle and Gailly 2015; Maresch et al. 2016). However, since the Human Capital Theory suggests that multidisciplinary teams foster an innovative mindset (Becker 1994) and that entrepreneurial teams composed of members with different backgrounds perform better than others (Colombo and Grilli 2005), it is important to analyse the entrepreneurship teaching model in a multidisciplinary environment. In fact, as suggested by Blank and Dorf (2012), start-ups are mostly a team journey where everyone has "power" and it is better if each member has different "power". Moreover, Reynolds and Lewis (2017) found that teams solve problems faster when they are more cognitively diverse. Therefore, a multidisciplinary team seems to be more suitable for a start-up team. In short, as suggested by Rauch and Hulsink (2015), it is important to carry out studies on entrepreneurship programmes that are offered to students from different fields of study and with different educational levels.

To fill this gap, this study aims to explain how entrepreneurship should be taught in a multidisciplinary environment. To do this, an exploratory single case study has been examined. An entrepreneurial courses carried out in 2018 by the Contamination Lab of Turin (CLabTo) in Italy has been considered and analysed. CLabTo is a joint-entrepreneurship programme that was developed by the Politecnico di Torino and the University of Turin that is aimed at increasing the entrepreneurial skills and intentions of their students through a challenge-based entrepreneurial programme. The entrepreneurship courses are challenge-based, because it has been suggested in the literature that practical entrepreneurship teaching models work better than theoretical ones (e.g., Honig 2004; Rasmussen and Sørheim 2006; Pittaway and Cope 2007; Kassean et al. 2015; Campos et al. 2017). In the present case, two of the authors have worked as key managers of CLabTo, and they have therefore explained how to adapt an entrepreneurship programme to a multidisciplinary environment. To do this, the structure proposed by Thursby et al. (2009) was adopted. Moreover, pre- and post-surveys were conducted in order to understand the obstacles and opportunities of this entrepreneurship programme from the students' perspective and to analyse the qualitative effect of this entrepreneurship programme on entrepreneurial skills and EI. The questions on entrepreneurial skills and EI were based on the Global University Entrepreneurial Spirit Students' 
Survey (GUESSS ${ }^{1}$ ). However, since CLabTo was created in 2017, only 62 participants were available for the surveys. Although the response rate was very high (90.3\%), only 56 participants answered, and no control sample was available. Therefore, the results, which are based on the pre- and post-surveys, are only qualitative.

First, our results show that it is easier to create a multidisciplinary entrepreneurship course as an extracurricular university course, since it may be difficult to overcome certain university policies. In addition, it is shown that, in order to teach entrepreneurship in a multidisciplinary environment, it is important to create a team with different competencies, as well as different cognitive and decision-making skills, as Thursby et al. (2009) suggested. In order to do this, we asked some Psychology researchers to create the teams on the basis of these skills. Moreover, professors from different fields of study were involved in the teaching programme, which was directed towards students from multidisciplinary backgrounds, thus lectures and insights from different fields of study were made available to the students. According to the obtained feedback from the students, they appreciated this aspect of CLabTo teaching. However, from the CLabTo's team's perspective, cooperating with professors that were not particularly involved in the programme was a challenging task, because it involved explaining the goals of the programme and asking them to change some aspects of their usual way of teaching to address a heterogeneous audience. Moreover, entrepreneurship education and design thinking were mixed in order to develop a challenge-based entrepreneurship course, including design methods, cognitive processes, techniques and sensibility to solve problems, as suggested by Glen et al. (2014). Even though a challenge-based entrepreneurship course can be more challenging to teach than an ordinary university course, it facilitates discussion and interaction between students and professors. In fact, according to Béchard and Grégoire (2005), who presented three teaching models, we are currently applying the Demand model, which has been defined as a practically-oriented entrepreneurship teaching model in which the role of the professor is that of a tutor and facilitator (Béchard and Grégoire 2005). In addition, a challenge-based entrepreneurship programme allows different actors in the local entrepreneurial ecosystem (e.g., corporations, student-led entrepreneurial organisations, incubators) to be integrated in the programme. It is also explained what the obstacles and opportunities of these programs are and how to improve them. Moreover, on the basis of the pre- and post-survey, our analyses show that the students' overall perception of their abilities to work in a multidisciplinary team, as well as that of their entrepreneurial skills, increased slightly. Interestingly, the greatest growth in the students' perception of their entrepreneurial skills pertained to the setting up of a professional network. Lastly, it has been found that the students' entrepreneurial intention increased. However, these results, which are based on the pre- and post-surveys, can only be considered qualitative, since the sample consisted of only 56 participants, and no control sample was available Our study contributes to the theory of the literature on entrepreneurship since we present a new format of an entrepreneurship programme for a multidisciplinary environment based on the structure of Thursby et al. (2009). By so doing, we also answer the need expressed by Rauch and Hulsink (2015) for more studies on entrepreneurship programmes offered to students from different fields of study and with different educational levels. This study also applies a teaching model that was presented by Béchard and Grégoire (2005) and the design thinking on entrepreneurship education suggested by Glen et al. (2014). Moreover, our work also has practical implications, since it shows, through an exploratory case study, how it may be possible to create an entrepreneurship programme in a multidisciplinary environment. Therefore, it is hoped that this study may have some practical implications for those professors and policymakers who are interested in creating an entrepreneurship programme for students from different fields of study and with different education levels.

1 GUESSS is a large, global research project on student entrepreneurship. More information is available on: http:/ /www. guesssurvey.org/. 
The paper is structured as follows. The next section presents a literature review pertaining to our study. Section 3 describes the case study and presents details of the CLabTo programme in order to understand how it may be implemented in other environments. Section 4 presents the results of the CLabTo programme considering its structure, pedagogical approach and the pre- and post-surveys on the students' entrepreneurial skills and EI. Finally, Section 5 presents the conclusions, limits and implications for further research.

\section{Literature Review}

It has been more than 70 years since the first entrepreneurship course was developed at Harvard's Business School in 1947 (Katz 2003). After that date, the number of entrepreneurship courses has increased significantly all around the world (Katz 2003, 2008; Kuratko 2005; Solomon 2007; Fretschner and Weber 2013; Torrance et al. 2013). For instance, the number of entrepreneurship courses increased from just a handful in the 1970s to more than 2200 courses, in over 1600 schools, at the beginning of the 2000s (Katz 2003), to more than 5000 in 2008 (Torrance et al. 2013). This increase also depends on the fact that universities are now fostering entrepreneurial skills among their students as part of their so-called third-mission (Rasmussen and Sørheim 2006; Rideout and Gray 2013; Siegel and Wright 2015). According to GUESSS reports, the number of students that have not attended a course on entrepreneurship decreased from 62.4\% in 2014 (Sieger et al. 2014) to 55.4\% in 2016 (Sieger et al. 2016). This increasing number of entrepreneurship courses depends on the fact that entrepreneurship education is aimed at promoting entrepreneurial skills and intention (Dou et al. 2019). Moreover, entrepreneurship education can foster entrepreneurial ecosystems (Cavallo et al. 2018a, 2018b); Entrepreneurship activities can in fact stimulate economic growth and innovation capacity in a Country (e.g., Powers and McDougall 2005; Van Stel et al. 2005; Braunerhjelm et al. 2010; Galindo and Méndez 2014). Moreover, according to the Global Entrepreneurship Monitor, one of the major barriers to entrepreneurship is a lack of education (Rideout and Gray 2013). For instance, with reference to a very high-quality journal, Campos et al. (2017) have recently explained that a psychology-based personal entrepreneurship teaching model (which teaches a proactive mindset and focuses on entrepreneurial behaviour) has been more successful than a traditional entrepreneurship teaching model. In fact, Campos et al. (2017) found a statistically significant and positive impact of psychology-based personal entrepreneurship teaching models on the profit of start-ups, compared to traditional entrepreneurship teaching. Therefore, several policymakers around the world are fostering the creation of entrepreneurship education (Gibb 2011; O'Connor 2013; Hoppe 2016). In fact, the European Council has stressed that entrepreneurship education should be a priority strategy for sustainable, inclusive and economic growth (Curth et al. 2015). Thanks to the policies developed in Europe, Barba-Sánchez and Atienza-Sahuquillo (2016) explained that entrepreneurship is now being taught in Spanish primary schools. For instance, the regional government of Castilla y León in Spain has supported the creation of an entrepreneurship programme named "E-Vitamin programme" (Chatzichristou et al. 2015; Curth et al. 2015). Moreover, the government of the Netherlands has supported the creation of Centres of Entrepreneurship in universities to direct, organise and facilitate multidisciplinary, institution-wide entrepreneurship education with the goal of encouraging entrepreneurship across all educational institutions and between individual educational institutions (Chatzichristou et al. 2015). The European Commission has recently supported two Erasmus+ focused on entrepreneurship education: Entrepreneurship Education Ecosystems in Engineering and 
Technology ${ }^{2}$ (Varano et al. 2018) and the Listo Project ${ }^{3}$. The Chinese government developed a strategic initiative in 2014 to increase entrepreneurship education in educational institutions (Dou et al. 2019). Moreover, as an indirect effect of all this attention towards and policies to foster entrepreneurship education, students are also creating their own entrepreneurial organisations (such as the European Confederation of Junior Enterprises-JADE and Enactus) in order to improve their entrepreneurial skills through learning-by-doing (Pittaway et al. 2011, 2015; Preedy and Jones 2017). In addition, several organisations have developed programmes, surveys and frameworks to analyse and measure the impact of entrepreneurship education on the entrepreneurial skills and intentions of students, for example, GUESSS (Sieger et al. 2014, 2016), the National Survey of Entrepreneurship Education (Solomon 2007), the Entrepreneurship Education Project-EPP (Vanevenhoven and Liguori 2013), the Entrepreneurship Competence Framework-EntreComp (Bacigalupo et al. 2016), Assessment Tools and indicators for entrepreneurship Education-ASTE (Moberg et al. 2014), the Innovation Cluster for Entrepreneurship Education-ICEE (Johansen 2018), the Framework for Innovation and Entrepreneurship Support in Open Higher Education-INNOENTRE (Kyrgidou et al. 2016) and the Student Entrepreneurship Making Innovation-SEMI ${ }^{4}$

As suggested by Campos et al. (2017), how we teach entrepreneurship is important. However, the literature shows that entrepreneurship is taught by means of different teaching models, even within the same university (Martin et al. 2013; Bae et al. 2014; Rideout and Gray 2013; Nabi et al. 2017). In order to summarise and cluster all the differences that may arise between the different ways of teaching entrepreneurship, Béchard and Grégoire (2005) created a taxonomy of three different entrepreneurship teaching models: Supply, Demand and Competence models. The Supply model seems to be a theoretical-oriented teaching model, since the professor is just a presenter, the student is a passive learner and knowledge is theoretical. On the other hand, the Demand and Competence models seem to be practical-oriented teaching models, since the professor is a tutor and facilitator (in the Demand model) or a coach and developer (in the Competence model), the student is an active participant and knowledge is not theoretical (in either model). Several studies (e.g., Honig 2004; Rasmussen and Sørheim 2006; Pittaway and Cope 2007; Kassean et al. 2015) have pointed out that practical-oriented teaching models are more effective than theoretical ones. For instance, Kassean et al. (2015) found that students who engage in more entrepreneurship experiential learning activities report greater entrepreneurial intentions. These results may be due to the fact that entrepreneurship requires creativity and innovative skills that are more comparable with a practical-oriented teaching model. Rasmussen and Sørheim (2006) explained that a learning-by-doing approach that involves the students is important when teaching entrepreneurship, since it allows students to work in teams and they can also on occasion cooperate with inventors and external mentors. Moreover, these types of entrepreneurship programmes "give students the possibility to gain experience in a real business context where the formation of entrepreneurial teams is emphasised" (Rasmussen and Sørheim 2006, p. 192). In line with this, Honig (2004) showed that entrepreneurship courses should emphasise actions that will engage students in more complex, nonlinear thinking, and they should go beyond the traditional teaching model of, for example, writing a business plan. According to Pittaway and Cope (2007), in order to promote skills, and to introduce students to diversity and authenticity, entrepreneurship education

2 The Entrepreneurship Education Ecosystems in Engineering and Technology (E4T) Erasmus+ project is aimed at providing more engineering graduates with entrepreneurial ambition, culture and skills (Varano et al. 2018). More information is available on: https://sites.google.com/view/entrepreneurship-e4t/home.

3 The LISTO Erasmus+ project is aimed at developing strategies that may be used to create a university-wide awareness of innovation and entrepreneurship. The project brings together 3 universities from Europe and 7 from Latin America. More information is available on: http://listoproject.eu/.

4 The SEMI project is also aimed at understanding the impact of entrepreneurship education on the entrepreneurial skills and intention of students. The SEMI project was created by the MIT Innovation Initiative and the Entrepreneurship and Innovation Center (EIC) at the Politecnico di Torino. More information is available on: https:/ /innovation.mit.edu/blog-post/mit-innovation-initiative-and-entrepreneurship-and-innovation-center-atpolitecnico-di-torino-launch-the-semi-project/. 
needs to educate "for" entrepreneurship using experiential and action learning. Experiential activities in an entrepreneurship course include, but are not limited to, idea generation exercises, work on real case studies, the creation of a start-ups, feasibility studies, consulting projects, entrepreneur interviews, guest speakers, pitch and simulations (Kassean et al. 2015). In addition, according to Glen et al. (2014), design-thinking can be considered a new experiential activity for entrepreneurship education. In fact, Glen and colleagues stated that "a design-thinking pedagogy provides a very useful front end to the new approaches to entrepreneurship, in giving students much more useful guidance on how to carry out a productive and user-centred ideation process" (Glen et al. 2014, p. 662). This is derived from the fact that design-thinking pedagogy integrates the process of effectuation developed by Sarasvathy (2003) and the concept of testing and iteration developed by Blank and Dorf (2012). Sarasvathy (2003) explained that successful entrepreneurs engaged in a process of effectuation of meaningful experiments with a variety of options and strategies in order to obtain success. Moreover, Blank and Dorf (2012) emphasised the importance of testing and iteration in the process of start-up creation. These practical-oriented teaching models help students identify more opportunities (DeTienne and Chandler 2004; Honig 2004). In addition, entrepreneurship programmes can play a key role in promoting entrepreneurship in the local entrepreneurial ecosystem (Rasmussen and Sørheim 2006).

As a result of this attention towards entrepreneurship education, several scholars have studied this phenomenon (Nabi et al. 2017). Most the studies on entrepreneurship education have found that it has a positive impact on entrepreneurial skills (Peterman and Kennedy 2003; Wilson et al. 2007; Athayde 2009; Morris et al. 2013; Sánchez 2013) and on EI (Peterman and Kennedy 2003; Souitaris et al. 2007; Athayde 2009; Sánchez 2011, 2013; Martin et al. 2013; Walter et al. 2013; Bae et al. 2014; Zhang et al. 2014; Gielnik et al. 2015). For instance, on the basis of a pre-test and a post-test on a sample of 710 students, of which 347 attended an entrepreneurship course (experimental group), while 363 did not (control group), Sánchez (2013) found that the students in the experimental group showed an increase in their entrepreneurial skills and EI, whereas the students in the control group did not. On the other hand, only a few studies have found an insignificant (Fayolle et al. 2006; Garalis and Strazdienè 2007), negative (Mentoor and Friedrich 2007; Oosterbeek et al. 2010) or mixed (Von Graevenitz et al. 2010) impact of entrepreneurship education on students' entrepreneurial skills and EI. However, Valerio et al. (2014) explained that entrepreneurship education can lead to positive changes in entrepreneurial skills and EI. According to the GUESSS report, entrepreneurial skills include such abilities as creating new products and services, managing innovation within a firm, commercialising a new idea or development, building up a professional network, identifying new business opportunities, successfully managing a business and being a leader and communicator. However, other studies, such as that of the EntreComp presented by Bacigalupo et al. (2016), showed similar categorisations for these entrepreneurial skills. Although EI is defined as the desire to become an entrepreneur (Krueger et al. 2000), it often indicates the intention to become an entrepreneur right after the conclusion of ones studies or five years after to the conclusion of ones studies (Sieger et al. 2014, 2016). Several studies (e.g., Zellweger et al. 2011; Dohse and Walter 2012; Laspita et al. 2012; Criaco et al. 2017) identified EI five years after the conclusion of the studies. This result is because students usually work during these first five years (Peterman and Kennedy 2003). In this way, they can improve their knowledge of the market, increase their networking, save money and receive feedback on their business ideas during this period of time.

Nevertheless, entrepreneurship courses are usually taught to students from a specific field of study and/or to just one educational level, even though multidisciplinarity is important for entrepreneurship. In fact, entrepreneurship courses are often offered in business and management courses. However, the current popularity of entrepreneurship has led to an increase in the demand from students for entrepreneurship courses (Fiet 2001; Peterman and Kennedy 2003), not only from students from business and management schools, but also from sciences and technology, engineering, design and architecture, humanities, natural science and law schools (Rideout and Gray 2013). However, most the studies on entrepreneurship education have analysed entrepreneurship courses offered to students from a specific field of study and/or a single educational level (e.g., Arias et al. 2018, 
Barba-Sánchez and Atienza-Sahuquillo 2018) with only a few exceptions, such as the study carried out by Thursby et al. (2009). Thursby et al. (2009) in fact analysed a two-year entrepreneurship and innovation course that was offered to science and engineering PhD students together with law and MBA students in two universities in the USA. They explained the benefits and drawbacks of a multidisciplinary entrepreneurship and innovation course, and they found a positive and significant effect of the programme on the students' perception of their multidisciplinary capabilities. However, the course analysed by Thursby et al. (2009) was offered to students from specific fields of study. Therefore, it is important to carry out studies on multidisciplinary entrepreneurship courses (Rauch and Hulsink 2015), since the impact of entrepreneurship education might vary considerably according to the students' characteristics, for example, their fields of study and educational levels (Fayolle and Gailly 2015; Maresch et al. 2016). Moreover, the Human Capital Theory suggests that multidisciplinarity is important in entrepreneurship (Becker 1994; Colombo and Grilli 2005). Our study aims to fill this gap by conducting an exploratory analysis of a multidisciplinary entrepreneurship programme created and conducted in Turin.

\section{Methodology}

\subsection{Introduction to the CLabTo Programme}

In Italy, in response to the demand for new entrepreneurial education programmes, MIUR has formulated and financed a model that could be replicated in different cities and regions called Contamination Lab (CLab). The aim of these CLabs is to provide entrepreneurship courses in order to develop skills in students that would otherwise not be provided by traditional training. Overall, 22 CLabs were created in Italy until the end of 2018. Each of these structures is recognised at a ministerial level (Directorial Decree no. 3158 of 29 November 2016). Although the purpose of raising attention towards entrepreneurship education is shared by all the CLabs, each CLab has a certain degree of freedom about the topics they deal with, the specific goals of their programmes and their structures, which can vary according to the features of a city and region, such as the local entrepreneurial ecosystem (e.g., investors, incubators and other entrepreneurial actors).

CLabTo was set up and financed at the end of 2017, and it will continue to benefit from MIUR funds until 2020. CLabTo involves two universities: the Politecnico di Torino, which is principally a STEM university, and the University of Turin, which is related above all to natural sciences and humanities. The decision to merge the two universities was taken to ensure that students from each and every field of study and educational level could participate in the programme. CLabTo decided to mix entrepreneurship education and design thinking in order to develop a challenge-based entrepreneurship course, which includes design methods, cognitive processes, techniques and sensibility for solving problems, as suggested by Glen et al. (2014). The aim of CLabTo is to create a multidisciplinary environment in which entrepreneurship is taught to students from different fields of study and with different educational levels. The intention of CLabTo is in fact to promote the entrepreneurial skills and intention of young Italian students. CLabTo was set up as an extracurricular programme, due to the difficulty of combining the policies of the two universities. These difficulties are due to the academic fragmentation of the disciplinary sectors in the two universities. In order to overcome these problems, CLabTo was created with the intent of providing a neutral place where entrepreneurship education could be experimented and the issues (e.g., university credits) arising from the creation of a new curricular programme developed by two distinct universities could be overcome. In short, CLabTo offers an extracurricular entrepreneurship programme drawn up by two universities in Turin to students from different fields of study and with different educational levels. CLabTo organises three different entrepreneurship courses, with three different intents and expected outcomes. Table 1 presents the three different entrepreneurship courses offered by CLabTo. 
Table 1. Scheme of the type 1, 2 and 3 courses. CLab: contamination lab.

\begin{tabular}{cccc}
\hline & Type 1 & Type 2 & Type 3 \\
\hline Name & CLab Workshop & CLab Sprint & CLab Master \\
Duration & 1 week or 2 weeks & 2 weeks-4 weeks & 2-6+ months \\
Goal & Idea generation & Prototyping & Start-up creation \\
\hline
\end{tabular}

The type 1 course, called CLab Workshop, is intended to stimulate the students to generate new ideas in the form of concepts, and it lasts 1 or 2 weeks. The type 2 course (CLab Sprint) includes prototyping, and it lasts from 2 weeks to 4 weeks. Lastly, the type 3 course (CLab Master) has the purpose of validating technical, business performance and IP studies so that any ideas and/or the prototypes may be developed to a more advanced stage, and it lasts from 2 to $6+$ months. These 3 CLab entrepreneurship courses are all challenge-based. We have adopted a challenge-based approach since the literature suggests using practical-oriented teaching models in entrepreneurship education (e.g., Honig 2004; Rasmussen and Sørheim 2006; Pittaway and Cope 2007; Kassean et al. 2015; Campos et al. 2017). The challenge-based nature of the CLabTo programme also makes it possible to involve other actors from the Turin entrepreneurial ecosystem, such as companies, student-led entrepreneurial organisations, incubators and entrepreneurs. We have also applied design thinking to help the students deal with the challenges. Design thinking helps students understand how to iterate their ideas, as well as to evaluate different strategies and opportunities, as suggested by Glen et al. (2014). By involving design professors, it is possible to integrate design methods (such as visualisation and prototyping, iterative exploration, planning and analysis) with entrepreneurial education, thus offering the students useful guidance on how to carry out a productive and user-centred ideation process. The integration of design thinking in entrepreneurship education can be taken as a starting point for other academics, researchers and universities interested in creating a multidisciplinary challenge-based programme.

Moreover, the CLabTo programme offers students the opportunity to test their theoretical knowledge in a real case, in multidisciplinary teamwork and therefore to learn from others. Every participant provides his/her knowledge and expertise to a programme where there is room to make mistakes, test and experiment. Moreover, since there is no exam, the students feel free to make mistakes, to ask questions and to test hypotheses. CLabTo collects students who are interested in entrepreneurship, regardless of their curricula, provided they are or have been enrolled at university. In addition, the teachers use the Demand model set up by Béchard and Grégoire (2005) to make students and professors interact and to enhance the active role of students. The CLabTo programme encourages students to create interdisciplinary working groups, facilitated by team-building exercises, which are supervised by Psychology researchers. In fact, CLabTo aims to foster a multidisciplinary environment in order to raise the enhancement of the differences in perspective and how students elaborate and process information, as well as how they think about and engage with new and complex situations, as suggested by Reynolds and Lewis $(2017)^{5}$. Moreover, as explained in the literature review, multidisciplinary is important for entrepreneurship. During the proposed entrepreneurship courses, the composition of the teams was tracked in order to ensure a certain degree of cognitive diversity, which has been hypothesised to help students solve tasks quickly.

\subsection{Study Population and Multidisciplinarity}

In this paper, we refer to the study population with data regarding all the students who participated in the CLabTo entrepreneurship courses. So far, three courses have been organised, two type1 CLab Workshops and one type2 CLab Sprint. From July to December 2018, 62 students took

5 The difference in perspectives and how students elaborate and process information, as well as how they think about and engage in new and complex situations is defined as "cognitive diversity" by Reynolds and Lewis (2017). 
part in these courses, and these students represent the study population. A total of $78 \%$ of the students who applied for the courses were accepted, and they were accepted on the basis of their curricula, motivation letters and oral interviews. This rather long selection process was adopted in order to avoid considering the average of marks of the students, which proved to be a poor criterion for the identification of entrepreneurship. Moreover, the final mark changed drastically from one course of study to another, and thus did not represent a satisfactory criterion. For this reason, we evaluated candidates by considering their motivation and expectations, their attitude to working in groups and their field of study in order to ensure multidisciplinarity. A dropout rate of $12.5 \%$ was observed before the course began, while the dropout rate during the course was $11.4 \%$. The first dropout rate refers to students who never started the programme, while the latter refers to students who started the programme but did not complete it, due to discrepancies with other group members, underestimation of the workload, or incompatibility with the other activities of the students. Of the 102 enrolled students, 62 of them successfully completed the programme, i.e., $77.5 \%$ of the initially enrolled students (Table 2).

Table 2. Number of males, females and the total students who (i) responded to the challenge, (ii) were admitted to the CLab programme (iii) started the programme (iv) completed the programme.

\begin{tabular}{cccc}
\hline & Males & Females & TOTAL \\
\hline Number of students who responded to the challenge & 58 & 44 & 102 \\
Number of students who were admitted to the CLab programme & 48 & 32 & 80 \\
Number of students who started the programme & 40 & 30 & 70 \\
Number of students who completed the programme (study population) & 38 & 24 & 62 \\
\hline
\end{tabular}

The study population of the entrepreneurship courses at CLabTo was generally aged between 20 and 34 years, with an average age of 25 years. Figure 1 shows the age distribution of the study population, where a peak can be observed between 25 and 26 years.

\section{POPULATION - Age distribution}

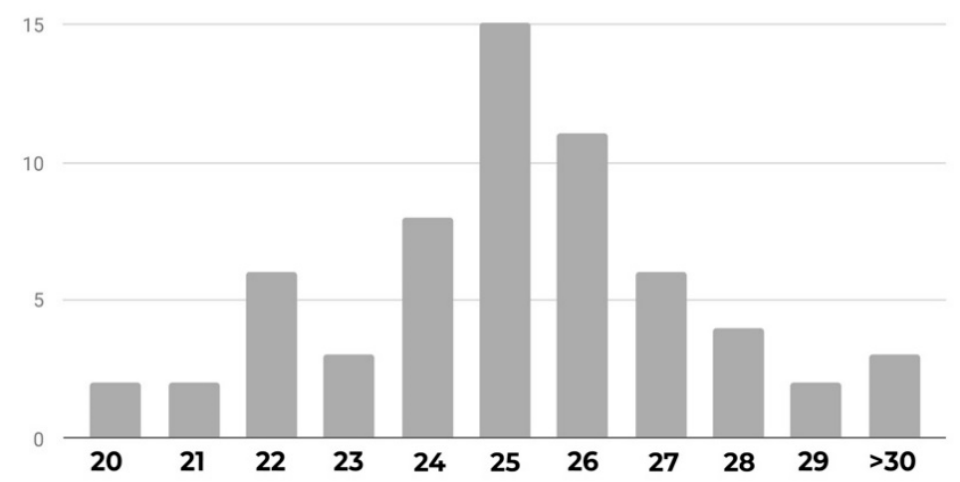

Figure 1. Age distribution.

The study population was composed of $61 \%$ of men and $39 \%$ of women. Of these, $75 \%$ were MSc students (ongoing or graduated), 25.5\% were BSc students (ongoing or graduated) and the remainder were $\mathrm{PhD}$ candidates (ongoing). It can be noticed, in Table 3, that $26 \%$ of the students came from humanities, $21 \%$ of the students were engineers, $19 \%$ came from management or management engineering, $18 \%$ were designers or architects and $16 \%$ had a natural science background. These categories were identified according to Thursby et al. (2009). However, unlike the Thursby et al. (2009) case, students from any field of study may participate in CLabTo, and two extra categories, that is, Design and Architecture and Humanities, were added. Since only 2 students had a Law background, the law students have been considered together with the humanity students. 
Table 3. Students who completed the programme divided according to their fields of study.

\begin{tabular}{ccc}
\hline Field of Study & Number of Students & $\%$ \\
\hline Design and Architecture & 11 & $18 \%$ \\
Engineering & 13 & $21 \%$ \\
Humanities & 16 & $26 \%$ \\
Management & 12 & $19 \%$ \\
Natural Science & 10 & $16 \%$ \\
TOTAL & 62 & $100 \%$ \\
\hline
\end{tabular}

This diverse and extremely multidisciplinary sample was a good starting point for the creation of 16 heterogeneous teams, as shown in the result section. To provide the necessary skills and to create a multidisciplinary environment, professors with different experience and from different departments and universities were involved in the challenge. This is an important aspect for CLabTo, which will hopefully be able to increase multidisciplinary collaboration, not only for students, but also for teachers. During the courses, the students are trained on challenge-specific topics, not only by the professors, but also by university faculty members (both professors and researchers) and by industry mentors and entrepreneurs. In 2018, a total of 24 teachers were involved in the three entrepreneurship courses, with $25 \%$ of female professors. Table 4 presents the number of professors divided according to their research fields.

Table 4. Number of professors divided according to their research fields.

\begin{tabular}{cc}
\hline Research Field & Number of Teachers \\
\hline Entrepreneurship & 2 \\
Psychology & 2 \\
Design & 1 \\
Sustainability & 3 \\
Digital innovation & 5 \\
Communication & 1 \\
Challenge-specific topics & 10 \\
TOTAL & 24 \\
\hline
\end{tabular}

As can be observed in Table 4, challenge-specific professors were predominant, due to the challenge-based nature of the programme. This predominance is justified by the fact that the other professors participated in more courses offered by CLabTo, while the challenge-specific ones are identified according to the topic of one specific challenge of a course. This aspect increases the difficulty of preparing the programme, because each challenge requires ad hoc teaching planning. With this careful teaching planning, our intention is to provide the same technical background to students who come from different fields of study. The organisation of these classes is dealt with in detail in the result section, and the students' feedback is commented on.

\subsection{Survey Description}

The essential information of the surveys is described in this section. Both pre- and post-surveys were developed to assess the students' perceptions of their skills or multidisciplinary competencies on entry to and exit from the course (Thursby et al. 2009). The survey also included open questions, such as "What worked best?" and text boxes in which the students could write their comments and suggestions. The data we gained from these surveys allowed us to understand how to improve the programme in the future, to evaluate student learning effects across degree programmes and the entrepreneurship teaching model used, as well as the students' perception of multidisciplinary abilities, entrepreneurial skills and intention. The pre- and post-surveys were based on literature. For instance, our questions regarding the role of teachers and students were derived from Béchard and Grégoire (2005), while the questions on entrepreneurial skills and EI were based on the GUESSS project survey. 
As far as EI is concerned, we decided to measure EI 5 years after the completion of the students studies. The 5-year period was chosen because students are usually employed immediately after the completion of their studies (Peterman and Kennedy 2003). This is explained considering the students' need to acquire the knowledge necessary to understand markets, take part in networking, put money aside, etc. The question on EI 5 years after the completion of studies was in fact found to be consistent with the definition of EI presented by Krueger et al. (2000). We attributed $1=$ yes when the students indicated "Entrepreneur" as their intention; $0=$ no otherwise. This is in line with the approaches adopted in other similar studies (Zellweger et al. 2011; Dohse and Walter 2012; Laspita et al. 2012; Criaco et al. 2017) to measure EI.

Appendix A presents the pre- and post-questionnaires used in this work.

\section{Results}

The results of the two questionnaires (pre- and post-surveys), which were sent to all the participants in the CLabTo entrepreneurship courses, have been used to summarise the results. A high response rate of $90.3 \%$ (56 students out of 62) answered both the questionnaires. The surveys were administered to participants before and after the course, and they are here referred to as the pre-course and post-course surveys.

\subsection{Implications Derived from the Students' Feedback}

\subsubsection{Multidisciplinarity in Team Composition and Teaching}

As previously noted, the multidisciplinary team approach is a key element of the programme (Thursby et al. 2009). Setting up the teams in the first two days of the course was useful since the choice of team members was based on real skills rather than affinity. During these two days, the students were required to form their teams, and they were provided with meeting opportunities, such as breakfast and lunch, and team-building exercises. The team building training was based on several activities oriented towards expressing: (a) the cognitive style of the students (need for closure), which is the way in which an individual gets to know others and becomes involved, (b) the decision-making style of the students, (c) the expectations, (d) the competence of the individuals to work in groups (De Jong et al. 2016; Rousseau et al. 2006; Salas et al. 2005). On the basis of this information, the team of psychologists identified reference anchors in relation to the outcome of the different activities performed during this team building process. The psychologists tried to mask those anchors to other participants with valid criteria, and to identify, for example, relevant topics to make sure that the interests of all the students would ill converge.

The composition of the student teams, divided into the three courses offered by CLabTo, is schematized in Figure 2, where the winning teams are also highlighted within a black frame. It is possible to observe, from Figure 2, that the ideal team is not always the one that includes 4 students from 4 different fields of study and that, in some cases, there are two students with similar backgrounds. This happened because although the psychologists informed the students about the importance of multidisciplinarity, and encouraged them to form heterogeneous teams, in the end, the students themselves had to decide, on the basis of the teachers' advice, character affinities and shared interests, with whom to form the teams.

According to the students, teamwork is the most frequently mentioned benefit of the programme. For example, in the exit surveys, the students were asked: "What worked best during the programme?" Of the 56 respondents, 38 of them listed "team" or "teamwork" as one of the most important aspects of the programme, as shown in some of the following comments made by the students:

- "The advice of the group of psychologists for the creation of groups"

- "Working in a group with different skills"

- "Multidisciplinary allowed us to develop a real project" 
- "Interacting with different people coming from different universities. This meant that each of us put his/her own expertise into the project"

- "Interdisciplinary groups"

- "Being all immersed in something new and unexpected. Regardless of the background, perceiving yourself as similar to others and being able to create in an environment without prejudices and that is only aimed at your growth"

The importance of "teamwork" and "multidisciplinary" is in line with start-up journey proposed by Blank and Dorf (2012). According to Blank and Dorf, it is important to combine different backgrounds to foster entrepreneurship. In order to create these multidisciplinary teams, we believe that the role of psychologists is important.

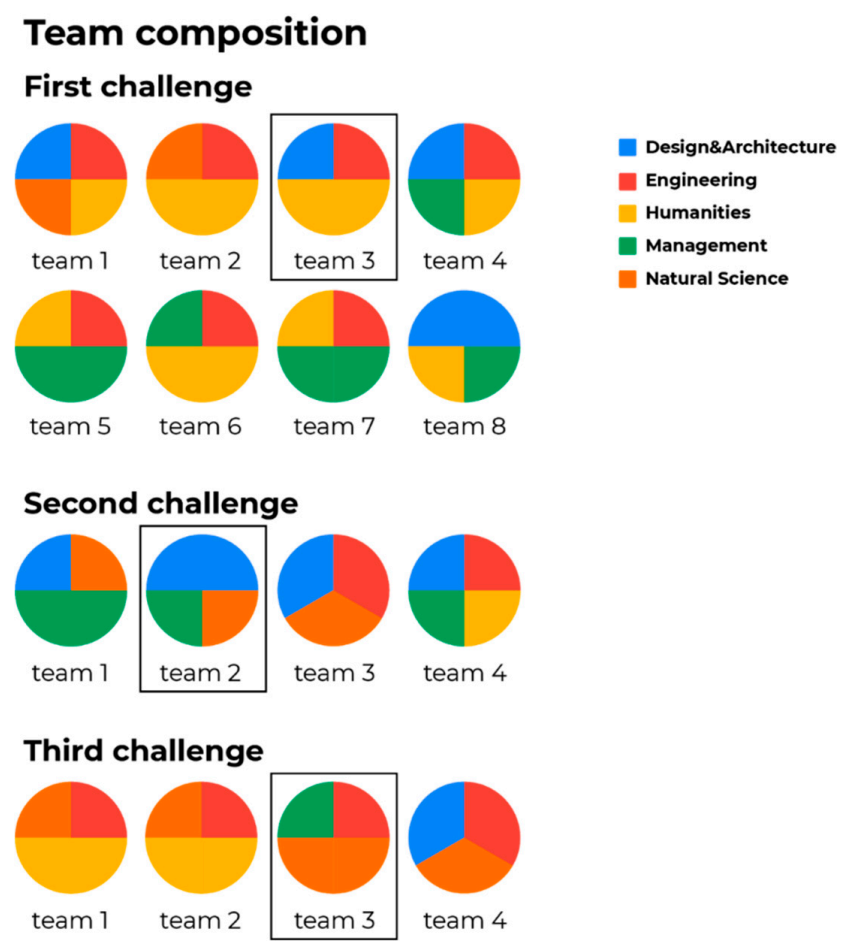

Figure 2. Team composition and winning teams.

As pointed out by Glen et al. (2014), it was observed that many of the technical students in the teams were more able to dissect phenomena into their component elements, while designers were more able to engage in synthesis, that is, in organising the various pieces into larger systems and ideas (Glen et al. 2014). For instance, in a multidisciplinary team, the interaction between technical, management and design students led to a new vision of a refrigerator. In this team, the students with a technical background provided the technical requirements (such as how a refrigeration works and the requirements of food conservation), the design students organised the information by connecting the user requirements, user behaviour, the domestic environment and food requirements into a larger system, while the management students highlighted the market possibilities for each solution and pointed out the socio-economic context of the product as well as the economic feasibility of its production.

The students were asked to what extent they felt the multidisciplinary experience was useful for their team. Their answers show it was the most appreciated aspect, with an average of $4.55 / 5$, thus confirming that the multidisciplinarity promoted by CLabTo has been extremely enriching. In this regard, it should be noted that the training provided to the students was also of a multidisciplinary nature, as it involved professors and experts from different fields of study. The heterogeneity of the audience pointed out the need for more interactivity and engagement, which was facilitated by the 
limited number of students in each entrepreneurship course (maximum 32 students), and the teachers changed their way of teaching accordingly. The approach that was adopted appears to have been successful, as can be seen from the following comments made by the students in response to the question "What worked best?":

- "Expert interventions. They have been very useful to approach a new way of assessing the challenge"

- "The initial lessons of the various professors allowed us to focus and deepen the theme in question"

- "The insights given by the lessons and the mixed groups were good incentives to look for new ideas"

- "The multidisciplinarynature of the lessons and the teams"

This result is very interesting, because most entrepreneurship courses are taught by entrepreneurship professor(s) with occasional guest speakers (usually successful local entrepreneurs). Our results show that students appreciated the lessons made by various professors from different fields of study. This may indicate that to teach in a multidisciplinary environment it is necessary to involve professors from different fields of study.

The perception of students about their role was mainly that of "active participant with a strong interaction with teachers" and the role of the teachers was mainly "as tutor and facilitator". This result indicates that the CLabTo programme is of the Demand model type presented by Béchard and Grégoire (2005), since the students play an active role and the professors are tutors and facilitators (Béchard and Grégoire 2005). This may derive to the challenge-based programme that encourages debate and exchange of feedback between students and teachers from different fields of study and research. Moreover, in a challenge-based entrepreneurship course, students have to work in a team with the goal of presenting their project at the end of the course. By doing this, students enhance their entrepreneurial abilities through learning-by-doing and experiential learning, as suggested in several works (e.g., Pittaway et al. 2011, 2015). This implies that students are active participants. In addition, the challenge-based entrepreneurship courses included design methods, cognitive processes, techniques, and sensibility for solving problems, as suggested by Glen et al. (2014), as well as brainstorming and prototyping, and surveys and semi-structured interviews involving potential users to gain greater awareness of their needs and expectations. Moreover, the students were asked whether they perceived the programme as being more theoretical (1) or practical (5), and to evaluate this feature over a range of 1 to 5 . An average score of 4 emerged, which means that the perceived programme was considered slightly more practical than theoretical. This indicates that the entrepreneurship programme applied a practical teaching model, as suggested in the literature (e.g., Honig 2004; Rasmussen and Sørheim 2006; Pittaway and Cope 2007). For instance, the teachers often asked the students to reconfigure the room layout since the room was designed to allow such reconfiguration, and asked the students questions instead of starting to explain, in order to understand what the students expected from the challenge and how much they knew about a certain topic. Other teachers asked students to do quick searches on google and to present the results of what they had understood. The use of visual supports (slides) and multimedia supports (videos, interviews, pieces of talk shows, etc.) creates an interactive and dynamic environment. Moreover, the CLabTo programme includes mid-term presentations in which professors give feedback to students, and appear during the team working activities in which they act as tutors and mentors. In fact, during the CLabTo courses, several hours are dedicated to team-work activities. The idea of professors and students being at the same level during the lessons, encourages students to play an active role by asking questions and expressing their doubts and ideas. This activity reinforces the creation of a neutral and safe environment, without judgments or marks, in which professors are willing to listen to students and also to learn from them. The learning-by-doing approach, in which students, in addition to theory, also have to do team-work activities on a real case, is also emphasised. Moreover, the challenge-based nature of the programme allows other actors of the entrepreneurial ecosystem to be involved, such as corporations, student-led entrepreneurial organisations and incubators. We have already worked 
with Junior Enterprise Torino Politecnico $\left(\mathrm{JEToP}^{6}\right)$ and Visionary ${ }^{7}$, two student-led entrepreneurial organisations who contacted us to set up a challenge. We have also worked with different actors, such as corporations (IREN ${ }^{8}$ to name one), the Incubatore Imprese Innovative del Politecnico di Torino- $-\mathrm{I}^{3} \mathrm{P}^{9}$ incubator and Fablab ${ }^{10}$ Torino. Since the local entrepreneurial ecosystem can improve entrepreneurship (Stam 2015; Acs et al. 2017) and students can be important actors and may have important roles (Siegel and Wright 2015; Rissola et al. 2017), we believe it is important to include the local entrepreneurial ecosystem in the course. In this way, students know who the actors in the ecosystem are, what these actors do and how they can collaborate with them. The aforementioned actors were involved in the CLabTo programme as tutors, mentors and as members of the jury during the final pitches. Thanks to their feedback, the students learned what the main issues of start-ups are in their local context. The evaluation of the students on the basis of their pitch instead of a written or oral examination was also appreciated by the students, as can be seen from their free comments in answer to the question "What worked best?"

- "The final pitch with the jury was a great stimulus"

- "Time schedule, pitches, multidisciplinary lessons and teams"

We decided to evaluate the students' work on the basis of their pitch instead of a written or oral examination, as suggested by Béchard and Grégoire (2005), in order to better evaluate the students' teamwork. In fact, during the pitch, the students performed in an authentic situation.

\subsubsection{Obstacles/Opportunities}

\section{(1) Teaching}

As far as teaching is concerned, one of the aspects we highlighted is how time-consuming it is to arrange the teaching according to the topic of the challenge, and to involve professors who are willing to share the cause and purposes of CLabTo. In this complex environment, we found it difficult to coordinate the work of the different actors. Moreover, delivering a pedagogy that simultaneously engaged all the student groups was challenging. On occasion it was also challenging to explain the CLab philosophy and purposes to professors who were called on for a one-off appearance pertaining to specific challenges for a couple of hours, that is, those teachers we defined as "challenge-specific teachers". Therefore, the process of involving professors included an email exchange in which we sent a presentation of the CLabTo, a book of the past courses and a set of CLab teaching guidelines. Moreover, we noticed that the lack of attribution of academic credits, which makes this programme an extracurricular activity, sometimes led to a low attendance rate of the students at the classes. Therefore, although involving teachers from different fields of study has been proved to be important to create a multidisciplinary environment, but this has also proved to be an obstacle, since all the professors need to be involved in the program. It has been found that in order to involve all the professors in the entrepreneurship programme, it is important to have clear and easy teaching guidelines.

(2) Abilities to work in a multidisciplinary team

Four possible obstacles students may face/have faced during the programme related to multidisciplinarity (Table 5) are highlighted hereafter:

1. Integrating themselves in a new team

2. Sharing their thoughts with their peers

\footnotetext{
More information on JEToP is available on: https:/ /jetop.com/en/home-en/. More information on Visionary is available on: https://www.visionarydays.it/.

More information on IREN is available on: https: / / www.gruppoiren.it/.

More information on I3P is available on: https:/ / www.i3p.it/.

More information on FabLab Torino is available on: http:/ / fablabtorino.org/.
} 
3. Managing different opinions within a team

4. Working with students from different fields of study

Table 5. Obstacles students may face/had faced during the programme related to multidisciplinarity.

\begin{tabular}{lcccc}
\hline & $\begin{array}{c}\text { Integrating Yourself } \\
\text { in a New Team }\end{array}$ & $\begin{array}{c}\text { Sharing Your } \\
\text { Thoughts with } \\
\text { Your Peers }\end{array}$ & $\begin{array}{c}\text { Managing Different } \\
\text { Opinions within a Team }\end{array}$ & $\begin{array}{c}\text { Working with Students } \\
\text { from Different Fields } \\
\text { of Study }\end{array}$ \\
\hline $\begin{array}{c}\text { Pre-survey } \\
\text { Post-survey }\end{array}$ & 4.13 & 4.21 & 3.68 & 3.84 \\
\hline
\end{tabular}

In the pre- and post-surveys, the students expressed their perceived difficulties in performing one of the tasks listed above, and put 1 when they did not foresee any difficulty in performing the task and 5 if they thought the task was difficult. In other words, a higher answer is correlated with a lower perceived difficulty of a student in performing a task. Overall, the students' perception of their abilities to work in a multidisciplinary team (Table 5) has increased slightly. In fact, the perception of the students pertaining to each of the 4 potential obstacles decreased slightly after the course, since all their answers were basically higher in the post-survey. Therefore, CLabTo helped the students to face all of these obstacles.

(3) Overall

The students were asked several questions in order to understand how to improve the programme and assess whether the students perceived the programme as it had been intended. For instance, we asked how the students considered the time dedicated to

- $\quad$ Teamwork: 2.77

- $\quad$ Presentations (Pitches): 2.91

- Support received: 2.66

- Classes: 3.11

and to classify this time using a scale from 1 to 5 ( $1=$ insufficient, $3=$ adequate and $5=$ too long).

It emerged that the students' perception about the duration of classes was slightly overestimated, while they thought that the time spent on team work, presentations and support received should be increased. This is in line with the literature that suggest that entrepreneurship courses need to be practical-oriented (e.g., Honig 2004; Rasmussen and Sørheim 2006; Pittaway and Cope 2007) and students therefore need less time dedicated to classes and more to time to working in teams and to preparing and receiving feedback from their presentations. As far as the overall duration of the courses is concerned (evaluated 1 = insufficient, $3=$ adequate, $5=$ too long), A mark of 2.68 was obtained, which reflects the previous assessments, with a perception of the programme being slightly shorter than expected. The students found that the material provided as a support to develop their ideas was satisfactory. This aspect was also evaluated over a range from 1 to 5 (where $1=$ insufficient, $3=$ adequate, $5=$ too much), and their answers to the question "Were the available materials sufficient for the realisation of the idea?" resulted in an average mark of 3.57/5. However, when focusing on teaching, the students complained about too little assistance during the team-work activities. Therefore, it is important to increase the mentorship time during the team-work activities and to obtain useful feedback from professors from different fields of study and actors from the entrepreneurial ecosystem.

\subsubsection{Implications on the Structure of the Programme}

First, we found that it is easier to create a multidisciplinary entrepreneurship course as an extracurricular university course, since university policies can be challenging to overcome. Moreover, since with the courses include students from different fields of study from two universities, it can be even more challenging. However, participating in an extracurricular university course allows us to 
select students who are really interested in the programme. During this first year of activity, we learned how to include design methods, cognitive processes and problem-solving techniques, as suggested by Glen et al. (2014). In the first few days, teams were encouraged to start working together during a brainstorming session, with the aim of enabling each student to express how his/her expertise could be used in relation to the topic of the challenge. This process led the students to exchange information and to understand how to interact with each other. Furthermore, during this activity, the students produced charts containing words, sketched images, connections and key concepts which represented the starting point for the following phases. In addition, the students were encouraged to investigate user needs through surveys and semi-structured interviews, and to test their ideas through processes of rough prototyping up to working prototypes of technologies, as in the case of the Type 2 class.

As far as training is concerned, we decided to prepare our own courses and material instead of drawing on those of the two involved universities. The main reasons why the programme could not benefit from the teaching of ongoing courses is that they are difficult to access and specific topics had to be dealt with on specific days and time, within the limited time of the challenge. Another important reason is that the classes had to balance the differences in the students' fields of study, with some parts being kept generic and easily understandable through the use of examples and case studies, while some more technical information was provided to the students who had the background necessary to understand it and use it during the team-work activities. The key for the class structure is in fact a delivery that informs those with limited backgrounds, while avoiding boring those with in-depth knowledge (Thursby et al. 2009). Thus, our classes tended to focus on content for an hour or two. In our opinion, multidisciplinary teams need the same degree of heterogeneity in teaching delivery, covering different fields, in order to rearrange information in a valuable manner. A better management of time, an extension of the length of the programme (Table 6) and the need to increase the presence of tutors are all among the aspects that need to be improved. From the results shown in the previous section, it has emerged that the time spent on lessons was overestimated compared to what the students expected as support for their specific projects. Moreover, during the first two courses, it emerged that $50 \%$ of the students involved in the first course found the duration of the programme, that is, two weeks, was adequate, $26 \%$ found the idea generation period too long, while $73 \%$ of the students in the second course complained about a lack of time, because a prototyping phase was introduced without the total length of the challenge being changed. Thus, we concluded that the introduction of prototyping requires the addition of an extra week dedicated to the prototype, and up to another five weeks to obtain a satisfactory prototype and iterate the concept.

Table 6. Scheme of the type 1, 2 and 3 courses revised in the duration.

\begin{tabular}{cccc}
\hline & Type 1 & Type 2 & Type 3 \\
\hline Name & CLab Workshop & CLab Sprint & CLab Master \\
Duration & 1 week-3 weeks & 3 weeks-8 weeks & 2-6+ months \\
Goal & Idea generation & Prototyping & Start-up creation \\
\hline
\end{tabular}

We believe that these three types of entrepreneurship courses may be useful to develop the entrepreneurial skills and EI of the students and to allow professors to have enough time to work with students in order to reach their goals. The goal of this section and the case study is to provide a guide to those who want to experiment with a multidisciplinary and challenge-based entrepreneurial education programme.

\subsection{Pre-Post Results on Entrepreneurial Skills and EI}

\subsubsection{Entrepreneurial Skills}

In order to assess the extent to which CLabTo classes and team experiences contribute to fostering the professional development of students, they were asked, in both pre- and post-surveys, to provide 
a self-assessment of their capabilities and perceived expertise in each of six skills listed in Table 7, which are derived from the GUESSS project.

Table 7. Six skills on which the students were asked to give a self-assessment.

\begin{tabular}{|c|c|c|c|c|c|}
\hline \multicolumn{6}{|c|}{ Entrepreneurial Skills } \\
\hline $\begin{array}{l}\text { Creating new } \\
\text { products and } \\
\text { services }\end{array}$ & $\begin{array}{c}\text { Managing } \\
\text { innovation } \\
\text { within a firm }\end{array}$ & $\begin{array}{l}\text { Commercialising } \\
\text { a new idea or } \\
\text { development }\end{array}$ & $\begin{array}{l}\text { Building up a } \\
\text { professional } \\
\text { network }\end{array}$ & $\begin{array}{c}\text { Identifying } \\
\text { new business } \\
\text { opportunities }\end{array}$ & $\begin{array}{c}\text { Successfully } \\
\text { managing a } \\
\text { business }\end{array}$ \\
\hline
\end{tabular}

The first three items refer explicitly to the innovation and development of new ideas/products/services. The fourth one is about belonging to a professional network, while the last two refer to the business aspects of vision and management. The students' ranked their perceived capabilities on these six entrepreneurial skills on a 5-point scale, where 1 stands for not capable, 2 for minimally capable, 3 for moderately capable, 4 for capable and 5 for extremely capable. The results are shown in Figure 3.

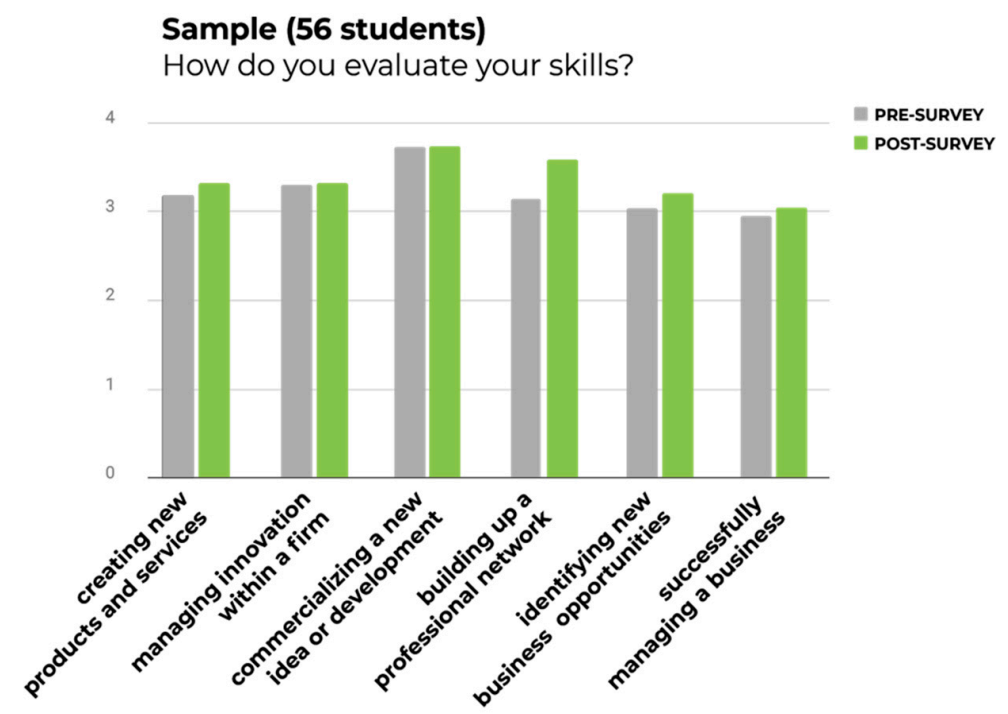

Figure 3. The overall perception of the students' entrepreneurial skills in the pre- and post-course questionnaires.

Although at first glance only some of the entrepreneurial skills (pre- and post-course) seem to have increased slightly, all the skills have increased, which is a good result, considering the limited duration of the programme. Therefore, our qualitative analyses show that the students' perception of their entrepreneurial skills overall increased slightly. This may be due to the fact that a practical-oriented teaching model was applied and that the students worked in a multidisciplinary environment. Moreover, we believe that these results are also due to the opportunities the students had of listening to professors from different fields of study and actors from the local entrepreneurial ecosystem. In other words, the entrepreneurial skill that increased the most for all the students is "Building up a professional network". This may be due to the fact that working in a small class allows students to know each other better and, therefore, to build up a professional network. Moreover, working with peers and professors from different fields of study and with actors from the local entrepreneurial ecosystem allows students to contact different people in the entrepreneurship domain.

If the data are analysed by breaking them down according to the types of students, it emerges interesting results. In fact, the remaining part of this section is dedicated to discussing this variety and exploring the data according to the education level (MSc and BSc) and to the fields of study (Design and Architecture, Engineering, Humanities, Management, Natural Science). The simplification highlighted 
in Figure 3 represents a balance between Masters and Bachelors as well as between different categories of students. The results pertaining to entry to the programme indicate that the MSc students had a higher perceived capability, while the BSc students had lower perceived capabilities. This probably derives from the fact that MSc students are older and may have already studied and/or had experience in the field. However, at the end of the programme, the situation is completely reversed. With the MSc students feeling they had achieved little or no gains, while the BSc students perceived a greater gain. This result could be attributed to the difficulty the students perceived in the programme, which led the almost trained professionals to be less confident of their capabilities after the programme. This may be because on entry the MSc students were confident they had the necessary skills to complete the course, but then encountered difficulties in completing the tasks or in obtaining some valid ideas on the topics of entrepreneurship and innovation. On the other hand, the BSc students, who had usually attended purely theoretical classes, may have been more willing to learn and they therefore found the course stimulating. Moreover, having the chance to work with MSc students probably made them feel much more competent and satisfied with the programme. It in fact emerged that the BSc students felt they had achieved a significant gain in all the skills. In relation to the field of study, the Design and Architecture students had a significant gain in each skill, except in "commercialising a new idea or development". They were followed by the engineering students, who had greater gains in the last four skills, but smaller gains in the first two. However, the engineering students always increased their skills, without experiencing any decrease. Contrary to expectations, the humanity students experienced a decrease in "successfully managing a business", and had little or no gain in the other two skills. The management students and natural scientist students experienced an increase in three skills, but a slight decrease in the other two. The management students experienced a notable increase in the "building up a professional network" skill and the natural science students acknowledged a notable increase in the "identifying new business opportunities" skill.

\subsubsection{Entrepreneurial Intention}

One of the aims of the study was to investigate the students' entrepreneurial intention 5 years after the completion of studies.

The general entrepreneurial intention 5 years after the completion of studies increased slightly, with the number rising from 10 pre-survey students to 13 post-survey ones (Table 8 ). This may be due to several aspects, such as the use of a practical teaching model in the programmes. Moreover, we believe that working in multidisciplinary teams on ones' own-idea is also an important aspect. In fact, entrepreneurship programmes "help to augment the perception of the important aspects of entrepreneurship and provide a realistic view of the problems it can involve" (Sánchez 2013, p. 458). However, only 6 of the students confirmed their EI before and after the challenge. It follows that 4 students who had expressed their EI at the beginning had abandoned this idea by the time they filled in the post-course questionnaire, while 7 students who had not expressed EI at the beginning instead mentioned it in the post-course questionnaire.

Table 8. Entrepreneurial intention 5 years after the completion of the studies.

\begin{tabular}{|c|c|c|c|}
\hline Entrepreneurial & Pre-Survey & Post-Survey & Result \\
\hline Intention in 5 Years & $\mathbf{N}^{\circ}$ of Students & $\mathbf{N}^{\circ}$ of Students & $\mathbf{N}^{\circ}$ of Students \\
\hline Total population & \multirow{2}{*}{10} & \multirow{2}{*}{13} & \multirow{2}{*}{ Increases by 3} \\
\hline (TOT 56 students) & & & \\
\hline
\end{tabular}

Figure 4 shows the fields of study of the students who expressed EI in the pre-course questionnaire. 


\section{Entrepreneurial intention PRE-SURVEY}

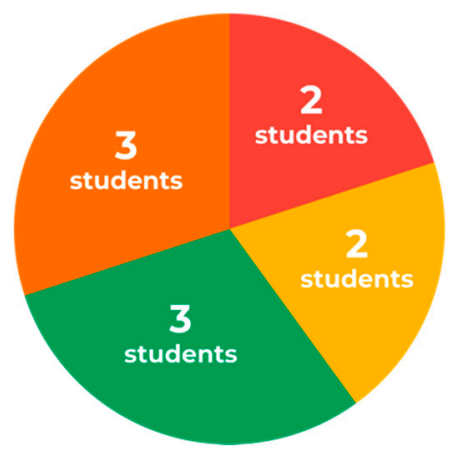

Design\&Architecture

Engineering

Humanities

Management

Natural Science

Figure 4. Pre-course EI composition (number of students).

At the beginning of the challenge, 4 out of 10 students interested in becoming entrepreneurs were female, while half of the students declared they spoke more than 2 languages. Johnstone et al. (2018) highlighted that language ability is an important resource for entrepreneurship and these data seem to support their thesis. Moreover, 8 of them were MSc students. Figure 5 shows the fields of study of the students who expressed EI in the post-course questionnaire.

\section{Entrepreneurial intention POST-SURVEY}
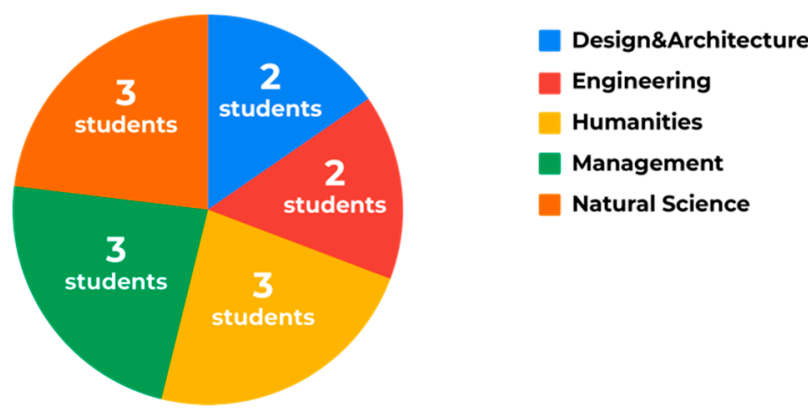

Figure 5. Post-course entrepreneurial intention (EI) composition (number of students).

At the end of the challenge, 4 out of 13 students who expressed EI were female, while 8 students declared they spoke more than 2 languages. These qualitative results suggested that there is a gender gap (Wilson et al. 2007; Criaco et al. 2017) and that the knowledge of languages (Johnstone et al. 2018) seems to be important for entrepreneurship. Moreover, 11 of who expressed EI were MSc students.

\section{Conclusions}

Even though several studies exist on entrepreneurship programmes (see Nabi et al. 2017 for a recent literature review), most them are based on a programme for students from a specific field of study and with the same educational level (e.g., Arias et al. 2018; Barba-Sánchez and Atienza-Sahuquillo 2018). Only a few studies have analysed entrepreneurship courses for students from different fields of study and with different educational levels, for example, the study carried out by Thursby et al. (2009). However, even the study conducted by Thursby et al. (2009) presents some limitations, as it describes an entrepreneurship programme that was only offered to students from specific fields of study (even though more than one) and from specific educational levels (PhD, MBA and Doctor of Jurisprudence). Therefore, it is not clear how entrepreneurship should be taught to students from different fields of study and with different educational levels (Rauch and Hulsink 2015). However, since the Human Capital Theory suggests that multidisciplinarity is important for 
innovation and entrepreneurship (Becker 1994; Colombo and Grilli 2005), introducing multidisciplinary into entrepreneurship programmes may be important.

The aim of the present study has been to fill this gap by carrying out an exploratory analysis, pertaining to a single case study, on an entrepreneurship programme offered to students from different fields of study and with different educational levels: the CLabTo programme. MIUR financed this entrepreneurship programme in a multidisciplinary environment in Turin, Italy. Two of the authors worked in the CLabTo in 2018, and thus the aim of this work has been to explain how to create an entrepreneurship programme for students from different fields of study and with different educational levels, following the structure of Thursby et al. (2009). We carried out pre- and post-surveys in order to understand the obstacles and opportunities perceived by the participants and the effect of this entrepreneurship programme on entrepreneurial skills and EI. The survey was based on the GUESSS survey. However, since the programme is new, we only had data regarding 56 out of 62 participants, and we did not have a control sample. Therefore, we only performed qualitative analyses.

On the basis of our experience, we discovered that it was easier to create this multidisciplinary entrepreneurship-type of programme as an extracurricular activity due to the complicated university policy on new curricular programmes for students from different fields of study and with different education levels. According to Thursby et al. (2009), we suggested creating teams in which students with different competencies, as well as cognitive and decision-making skills were involved. In fact, Psychology researchers were involved in creating the teams on the basis of the aforementioned skills. Each team that was formed showed a high degree of cognitive difference. In fact, each team included students from at least three different fields of study. In our opinion, multidisciplinary teams needed the same degree of heterogeneity in background of the teachers. In order to create a real multidisciplinary environment, we asked professors from different research fields to teach in the entrepreneurship courses. We believe that having teachers with different background scan help students receive feedback from different perspectives and increase their creativity. On the basis of the pre- and post-surveys, it was found that the students seemed to appreciate having multidisciplinary professors. As far as the teaching model is concerned, entrepreneurship education is currently being mixed with design thinking, as suggested by Glen et al. (2014), and a challenge-based approach is being adopted in order to facilitate the discussion and interaction between students and professors. In other words, on the basis of the three teaching models presented by Béchard and Grégoire (2005), we are applying the Demand model. Moreover, a challenge-based entrepreneurship programme has been developed, since the literature (e.g., Honig 2004; Rasmussen and Sørheim 2006; Pittaway and Cope 2007; Kassean et al. 2015; Campos et al. 2017) suggests using practical-oriented entrepreneurship teaching models, and other important actors in the Turin entrepreneurial ecosystem, such as corporations, student-led entrepreneurial organisations and incubators, have been included in the programme. We have also explained what the obstacles and opportunities of these programmes are and how to improve them. As a general result concerning the programme, CLabTo can be considered as a practical programme. It emerges that the students' perception about the duration of classes is slightly overestimated, while the time spent on team working, presentations and support received should be increased. As far as the overall duration of the courses is concerned, the students considered that the programme was slightly shorter than they had expected. As a result of the students' feedback, the length of the next courses will be changed, new forms of teaching and tutoring will be tested during the team-work activities and the programme will thus be improved to make it even more useful for students who decide to become entrepreneurs. The goal is now to identify students with EI and help them acquire capabilities that will be needed in their future career (Thursby et al. 2009). On the basis of the pre- and post-surveys, it has emerged that the students perceived that their understanding of how to work in a multidisciplinary team had increased slightly. As already highlighted by Thursby et al. (2009), by means of another entrepreneurial education programme (TIGER), although our data are self-reported perceptions, it is clear from our empirical analysis that the described programme has had some effects on the students' perceptions of their entrepreneurial abilities. Overall, we also found that the students' perception of 
their entrepreneurial skills increased, especially for "Building up a professional network", perhaps because the students worked in multidisciplinary team and cooperated with other people during the courses. Both on entry and exiting from the programme, some differences emerged for the field categories and MSc/BSc backgrounds as far as perceived capabilities are concerned. Moreover, the most significant gains were shown for the BSc students and designers, followed by the engineers. However, an overall increase in each skill was observed, which is a good result. Lastly, the results show that the students' entrepreneurial intention increased. However, since information was only available on a small sample, and no control sample was available, only perform qualitative analyses were performed. In short, this work has been aimed at increasing the knowledge on the importance of entrepreneurship education for students from different fields of study and with different levels of education. Such a study is important since multidisciplinary is relevant in entrepreneurship. Moreover, we believe that these entrepreneurship courses need to be practical-oriented. We also believe that this entrepreneurial programme could lead to cooperation with universities outside Italy, but this would require a non-trivial effort to convince different professors and universities to collaborate in a joint project.

\section{Limits and Future Research}

Our study presented some limitations that should be addressed in future research. The findings should be treated tentatively because of the exploratory nature of this research. In fact, a limitation of this work is that it is based on a single case study (CLabTo) and, since it refers to a new entrepreneurship programme, only limited data were available (56 answers), and no control sample. Therefore, only qualitative analyses were performed on the multidisciplinary entrepreneurship programme. Future research could analyse the differences between a multidisciplinary entrepreneurship programme and a non-multidisciplinary entrepreneurship programme, in terms of teaching model and impact of these two types of programmes on the students' entrepreneurial skills and EI through the administration of pre- and post-surveys to the participants. Moreover, since start-ups work on a global market, it could be interesting to create entrepreneurship programmes for students from different cultures. For instance, Varano et al. (2018) presented a new Erasmus+ project aimed at creating a transnational entrepreneurship programme for students. Similarly, Musteen et al. (2018) presented an international entrepreneurship programme. Future studies could therefore analyse the differences between entrepreneurship programmes offered to students from the same field of study and the same culture and entrepreneurship programmes offered to students from different fields of study and different cultures, in terms of teaching model and the impact of these two types of programmes on students' entrepreneurial skills and EI through the administration of pre-and post-surveys to the participants. Moreover, future studies could analyse the differences between multidisciplinary entrepreneurship programmes for students with the same culture and multidisciplinary entrepreneurship programmes for students with different cultures, in terms of teaching model and impact of these two programmes on students' entrepreneurial skills and EI through the administration of pre-and post-surveys to the participants. These studies could help those students who are interested in entrepreneurship, professors of entrepreneurship and policymakers to better understand how to teach entrepreneurship in situations of real complex dynamics and the impact of different entrepreneurship programmes on students' entrepreneurial skills and EI.

Moreover, Urbinati et al. (2018) suggested that information technology in entrepreneurship schools may be interesting. Therefore, future studies need to understand how to include technology (such as 3D printing), information technology (such as Artificial Intelligence and Blockchain) and social media (such as Facebook, Instagram and Twitter) in entrepreneurship programmes, since they are important for many start-ups. This may add to the emerging debate on digital entrepreneurship as a distinct research field (e.g., Nambisan 2017; Balocco et al. 2019). We also suggest using and analysing the impact of female professors in entrepreneurship education programmes, since several studies have suggested that this role model may be important to foster female entrepreneurship (e.g., 
Scherer et al. 1989; Díaz-García and Jiménez-Moreno 2010). Furthermore, since the entrepreneurial ecosystem is an important instrument to foster entrepreneurship (Stam 2015; Acs et al. 2017) and students may be important actors in this ecosystem (Siegel and Wright 2015; Rissola et al. 2017), future studies need to analyse the role of students in the entrepreneurial ecosystem. In other words, it could be interesting to understand whether, why and how students interact with the entrepreneurial ecosystem and what the obstacles and opportunities of their collaboration are within the entrepreneurial ecosystem. Lastly, since social start-ups are considered capable of providing innovative responses to social and environmental problems (EC European Commission 2011) and they are increasing (Arena et al. 2018), it is important to create ad hoc entrepreneurship programmes on social entrepreneurship (Viglialoro and Landoni 2019). Future studies could therefore analyse the differences between social entrepreneurship programmes and entrepreneurship programmes by not focusing on social entrepreneurship in terms of teaching models and the impact of these two programmes on students' entrepreneurial skills and EI through the administration of pre- and post-surveys to the participants.

Author Contributions: Conceptualisation, E.F. and E.P.; methodology, E.F. and G.S.; data curation, E.F. and G.S.; writing-original draft preparation, E.F. and G.S.; supervision, E.P.; project administration, E.F. and E.P.

Funding: This research was funded by the Ministero dell'Istruzione, dell'Università e della Ricerca (MIUR) PNR 2015/2020-Directorial Decree no. 3158 of 29 November 2016, grant number Prot. CL16JWECRH and the APC was funded by the same funder and with the same grant number.

Acknowledgments: First, special thanks are due to the professors who participated in the CLabTo. Moreover, we would like to thank Cristina Mosso and her Psychology research team for helping us create the teams during the courses and for describing this activity it in this paper. Lastly, we would also like to thank all the students who participated in the CLabTo programme and who responded to our pre- and post-surveys.

Conflicts of Interest: The authors declare no conflict of interest.

\section{Appendix A}

Question in the post-survey: To what extent do you feel the multidisciplinary experience was useful for your team?

\begin{tabular}{|c|c|c|c|c|}
\hline \multicolumn{5}{|c|}{5 point Likert scale } \\
\hline Strongly disagree & Rather disagree & Equal & Rather agree & Strongly agree \\
\hline
\end{tabular}

Question in the post-survey: What was the role of the teachers?

\begin{tabular}{|l|l|}
\hline & Choose one option \\
\hline as tutors and facilitators & \\
\hline as presenters & \\
\hline as coaches and developers & \\
\hline
\end{tabular}

Question in the post-survey: What was your role during the classes?

\begin{tabular}{|l|l|}
\hline & Choose one option \\
\hline As a passive learner & \\
\hline As an active participant, interacting with the teacher & \\
\hline As an active participant, playing a central role instead of the teacher during the lessons & \\
\hline
\end{tabular}

Question in the post-survey: "Did you perceive the programme as being more theoretical or practical?"

\begin{tabular}{|c|c|c|c|c|}
\hline \multicolumn{5}{|c|}{5 point Likert scale } \\
\hline Mainly theoretical & Rather theoretical & $\begin{array}{c}\text { Equally theoretical } \\
\text { and practical }\end{array}$ & Rather practical & Mainly practical \\
\hline
\end{tabular}

Question in the post-survey: How do you evaluate the... 


\begin{tabular}{|l|l|l|l|l|l|}
\hline \multicolumn{2}{|c|}{ Insufficient } & Low & Adequate & High & too much \\
\hline $\begin{array}{l}\text { Overall duration of the } \\
\text { courses }\end{array}$ & & & & & \\
\hline $\begin{array}{l}\text { Adequacy of the provided } \\
\text { materials }\end{array}$ & & & & & \\
\hline $\begin{array}{l}\text { Time dedicated to the } \\
\text { team-work activities }\end{array}$ & & & & & \\
\hline $\begin{array}{l}\text { Time dedicated to } \\
\text { presentations }\end{array}$ & & & & & \\
\hline Support received & & & & & \\
\hline Time dedicated to classes & & & & & \\
\hline
\end{tabular}

Question in the pre- and post-surveys: In your opinion, how difficult could it be/was it for you to perform the following activities?

\begin{tabular}{|c|c|c|c|c|c|}
\hline & \multicolumn{5}{|c|}{5 point Likert scale } \\
\hline & Very difficult & Difficult & $\begin{array}{c}\text { Neither difficult } \\
\text { nor easy }\end{array}$ & Easy & Very easy \\
\hline Integrate yourself in a new team & & & & & \\
\hline Share your thoughts with your peer & & & & & \\
\hline $\begin{array}{l}\text { Manage different opinions within a } \\
\text { team }\end{array}$ & & & & & \\
\hline $\begin{array}{l}\text { Work with students from different } \\
\text { fields of study }\end{array}$ & & & & & \\
\hline
\end{tabular}

Question in the pre- and post-surveys: Please indicate your level of competence in performing the following tasks:

\begin{tabular}{|c|c|c|c|c|c|}
\hline \multirow{2}{*}{$\begin{array}{c}\text { GUESSS } \\
\text { entrepreneurial } \\
\text { skills }^{11}\end{array}$} & \multicolumn{5}{|c|}{5 point Likert scale ${ }^{12}$} \\
\hline & $\begin{array}{c}\text { Very low } \\
\text { competence }\end{array}$ & $\begin{array}{c}\text { Low } \\
\text { competence }\end{array}$ & Adequate & $\begin{array}{c}\text { High } \\
\text { competence }\end{array}$ & $\begin{array}{c}\text { Very high } \\
\text { competence }\end{array}$ \\
\hline \multicolumn{6}{|l|}{$\begin{array}{l}\text { Creating new } \\
\text { products and } \\
\text { services }\end{array}$} \\
\hline \multicolumn{6}{|l|}{$\begin{array}{l}\text { Managing } \\
\text { innovation } \\
\text { within a firm }\end{array}$} \\
\hline \multicolumn{6}{|l|}{$\begin{array}{l}\text { Commercialising } \\
\text { a new idea or } \\
\text { development }\end{array}$} \\
\hline \multicolumn{6}{|l|}{$\begin{array}{l}\text { Building up a } \\
\text { professional } \\
\text { network }\end{array}$} \\
\hline \multicolumn{6}{|l|}{$\begin{array}{l}\text { Identifying } \\
\text { new business } \\
\text { opportunities }\end{array}$} \\
\hline $\begin{array}{l}\text { Successfully } \\
\text { managing a } \\
\text { business }\end{array}$ & & & & & \\
\hline
\end{tabular}

12 Unlike the GUESSS study based of a 7-point Likert scale, we adopted a 5 point Likert scale was adopted.

11 Unlike the GUESSS study, we did not consider the entrepreneurial skill "Being a leader and communicator". was not considered. 
Question in the pre- and post-surveys: "Which career path do you intend to pursue 5 years after the completion of your studies?"

\begin{tabular}{|l|c|c|}
\hline & Choose one option & EI? \\
\hline Employee in a small company (1-49 employees) & & no \\
\hline Employee in a medium-sized company (50-249 employees) & & no \\
\hline Employee in a large company (250 or more employees) & & no \\
\hline Employee in a non-profit organisation & & no \\
\hline Public employee (including the university) & & no \\
\hline Entrepreneur & & yes \\
\hline Other & & no \\
\hline
\end{tabular}

\section{References}

Acs, Zoltan J., Erik Stam, David B. Audretsch, and Allan O'Connor. 2017. The lineages of the entrepreneurial ecosystem approach. Small Business Economics 49: 1-10. [CrossRef]

Arena, Marika, Irene Bengo, Mario Calderini, and Veronica Chiodo. 2018. Unlocking finance for social tech start-ups: Is there a new opportunity space? Technological Forecasting and Social Change 127: 154-65. [CrossRef]

Arias, Enrique, Virginia Barba-Sánchez, Carmen Carrión, and Rafael Casado. 2018. Enhancing Entrepreneurship Education in a Master's Degree in Computer Engineering: A Project-Based Learning Approach. Administrative Sciences 8: 58. [CrossRef]

Athayde, Rosemary. 2009. Measuring enterprise potential in young people. Entrepreneurship Theory and Practice 33: 481-500. [CrossRef]

Bacigalupo, Margherita, Panagiotis Kampylis, Yves Punie, and Godelieve Van den Brande. 2016. EntreComp: The Entrepreneurship Competence Framework. Luxembourg: Publication Office of the European Union.

Bae, Tae Jun, Shanshan Qian, Chao Miao, and James O. Fiet. 2014. The relationship between entrepreneurship education and entrepreneurial intentions: A meta-analytic review. Entrepreneurship Theory and Practice 38: 217-54. [CrossRef]

Balocco, Raffaello, Angelo Cavallo, Antonio Ghezzi, and Jasmina Berbegal-Mirabent. 2019. Lean business models change process in digital entrepreneurship. Business Process Management Journal. [CrossRef]

Barba-Sánchez, Virginia, and Carlos Atienza-Sahuquillo. 2016. The development of entrepreneurship at school: The Spanish experience. Education and Training 58: 783-96. [CrossRef]

Barba-Sánchez, Virginia, and Carlos Atienza-Sahuquillo. 2018. Entrepreneurial intention among engineering students: The role of entrepreneurship education. European Research on Management and Business Economics 24: 53-61. [CrossRef]

Béchard, Jean-Pierre, and Denis Grégoire. 2005. Understanding teaching models in entrepreneurship for higher education. In The Dynamics of Learning Entrepreneurship in a Cross-Cultural University Context. Edited by Paula Kyrö and Camille Carrier. Tampere: Faculty of Education, University of Tampere, pp. 104-34.

Becker, Gary S. 1994. Human capital revisited. In Human Capital: A Theoretical and Empirical Analysis with Special Reference to Education, 3rd ed. Chicago: The University of Chicago Press, pp. 15-28.

Blank, Steve, and Bob Dorf. 2012. The Startup Owner's Manual: The Step-by-Step Guide for Building a Great Company. Pescadero: K and S. Ranch Publishers.

Braunerhjelm, Pontus, Zoltan J. Acs, David B. Audretsch, and Bo Carlsson. 2010. The missing link: Knowledge diffusion and entrepreneurship in endogenous growth. Small Business Economics 34: 105-25. [CrossRef]

Campos, Francisco, Michael Frese, Markus Goldstein, Leonardo Iacovone, Hillary C. Johnson, David McKenzie, and Mona Mensmann. 2017. Teaching personal initiative beats traditional training in boosting small business in West Africa. Science 357: 1287-90. [CrossRef] [PubMed]

Cavallo, Angelo, Antonio Ghezzi, and Raffaello Balocco. 2018a. Entrepreneurial ecosystem research: Present debates and future directions. International Entrepreneurship and Management Journal, 1-31. [CrossRef]

Cavallo, Angelo, Antonio Ghezzi, Alessandra Colombelli, and Gian Luca Casali. 2018b. Agglomeration dynamics of innovative start-ups in Italy beyond the industrial district era. International Entrepreneurship and Management Journal, 1-24. [CrossRef] 
Chatzichristou, Stelina, Anette Curth, Ilze Feifa, Martin Gosset, Martina Kadunc, Marie-Pierre Mosca, Patricia Vale, Naomi Williamson, Rebecca Allinson, and Anders Håkansson. 2015. Entrepreneurship Education: A Road to Success-13 Case Studies. Brussels: European Commission.

Colombo, Massimo G., and Luca Grilli. 2005. Founders' human capital and the growth of new technology-based firms: A competence-based view. Research Policy 34: 795-816. [CrossRef]

Criaco, Giuseppe, Philipp Sieger, Karl Wennberg, Francesco Chirico, and Tommaso Minola. 2017. Parents' performance in entrepreneurship as a "double-edged sword" for the intergenerational transmission of entrepreneurship. Small Business Economics 49: 841-64. [CrossRef]

Curth, Anette, Stelina Chatzichristou, Axelle Devaux, and Rebecca Allinson. 2015. Entrepreneurship Education: A Road to Success. A Compilation of Evidence on the Impact of Entrepreneurship Education Strategies and Measures. Belgium: European Commission.

De Jong, Bart A., Kurt T. Dirks, and Nicole Gillespie. 2016. Trust and Team Performance: A Meta-analysis of Main Effects, Moderators, and Covariates. Journal of Applied Psychology 101: 1134-50. [CrossRef] [PubMed]

DeTienne, Dawn R., and Gaylen N. Chandler. 2004. Opportunity identification and its role in the entrepreneurial classroom: A pedagogical approach and empirical test. Academy of Management Learning E Education 3: 242-57.

Díaz-García, Maria Cristina, and Juan Jiménez-Moreno. 2010. Entrepreneurial intention: The role of gender. International Entrepreneurship and Management Journal 6: 261-83. [CrossRef]

Dohse, Dirk, and Sascha G. Walter. 2012. Knowledge context and entrepreneurial intentions among students. Small Business Economics 39: 877-95. [CrossRef]

Dou, Xinhua, Xiajing Zhu, Jason Q. Zhang, and Jie Wang. 2019. Outcomes of entrepreneurship education in China: A customer experience management perspective. Journal of Business Research. [CrossRef]

EC European Commission. 2006. Recommendation of the European Parliament and of the Council of 18 December 2006 on key competences for lifelong learning. Official Journal of the European Union 30: L394/310.

EC European Commission. 2011. Social Business Initiative: Creating a Favourable Climate for Social Enterprises, Key Stakeholders in the Social Economy and Innovation. Communication from the Commission. Brussels: EC European Commission, October 25.

Fayolle, Alain, and Benoit Gailly. 2015. The impact of entrepreneurship education on entrepreneurial attitudes and intention: Hysteresis and persistence. Journal of Small Business Management 53: 75-93. [CrossRef]

Fayolle, Alain, Benoit Gailly, and Narjisse Lassas-Clerc. 2006. Assessing the impact of entrepreneurship education programmes: A new methodology. Journal of European Industrial Training 30: 701-20. [CrossRef]

Fiet, James O. 2001. The pedagogical side of entrepreneurship theory. Journal of Business Venturing 16: 101-17. [CrossRef]

Fretschner, Michael, and Susanne Weber. 2013. Measuring and understanding the effects of entrepreneurial awareness education. Journal of Small Business Management 51: 410-28. [CrossRef]

Galindo, Miguel-Ángel, and María Teresa Méndez. 2014. Entrepreneurship, economic growth, and innovation: Are feedback effects at work? Journal of Business Research 67: 825-29. [CrossRef]

Garalis, Algirdas, and Gražina Strazdienè. 2007. Entrepreneurial skills development via simulation business enterprise. Socialiniai Tyrimai 10: 39-48.

Gibb, Allan. 2011. Concepts into practice: Meeting the challenge of development of entrepreneurship educators around an innovative paradigm: The case of the International Entrepreneurship Educators' Programme (IEEP). International Journal of Entrepreneurial Behavior E Research 17: 146-65.

Gielnik, Michael M., Michael Frese, Audrey Kahara-Kawuki, Isaac W. Katono, Sarah Kyejjusa, Muhammed Ngoma, John Munene, Rebecca Namatovu-Dawa, Florence Nansubuga, Laura Orobia, and et al. 2015. Action and action-regulation in entrepreneurship: Evaluating a student training for promoting entrepreneurship. Academy of Management Learning E Education 14: 69-94.

Glen, Roy, Christy Suciu, and Christopher Baughn. 2014. The need for design thinking in business schools. Academy of Management Learning E Education 13: 653-67.

Honig, Benson. 2004. Entrepreneurship education: Toward a model of contingency-based business planning. Academy of Management Learning E Education 3: 258-73.

Hoppe, Magnus. 2016. Policy and entrepreneurship education. Small Business Economics 46: 13-29. [CrossRef] 
Johansen, Vegard. 2018. Innovation Cluster for Entrepreneurship Education. Lillehammer, Norway, Østlandsforskning/Eastern Norway Research Institute. Available online: http:/ /icee-eu.eu/component/ attachments / ?task=download\&id=623:ICEE-final-report (accessed on 1 February 2019).

Johnstone, Leanne, Mariana Pio Monteiro, Inês Ferreira, Johanna Westerlund, Roosa Aalto, and Jenni Marttinen. 2018. Language ability and entrepreneurship education: Necessary skills for Europe's start-ups? Journal of International Entrepreneurship 16: 369-97. [CrossRef]

Kassean, Hemant, Jeff Vanevenhoven, Eric Liguori, and Doan E. Winkel. 2015. Entrepreneurship education: A need for reflection, real-world experience and action. International Journal of Entrepreneurial Behavior $\mathcal{E}$ Research 21: 690-708.

Katz, Jerome A. 2003. The chronology and intellectual trajectory of American entrepreneurship education: 1876-1999. Journal of Business Venturing 18: 283-300. [CrossRef]

Katz, Jerome A. 2008. Fully mature but not fully legitimate: A different perspective on the state of entrepreneurship education. Journal of Small Business Management 46: 550-66. [CrossRef]

Krueger, Norris F., Michael D. Reilly, and Alan L. Carsrud. 2000. Competing models of entrepreneurial intentions. Journal of Business Venturing 15: 411-32. [CrossRef]

Kuratko, Donald F. 2005. The emergence of entrepreneurship education: Development, trends, and challenges. Entrepreneurship Theory and Practice 29: 577-97. [CrossRef]

Kyrgidou, Lida P., Theodosios Sapounidis, and Ioannis Stamelos. 2016. Entrepreneurship and Education: The "InnoEntre" Project. In Innovation and Entrepreneurship in Education. Bingley: Emerald Group Publishing Limited, pp. 131-46.

Laspita, Stavroula, Nicola Breugst, Stephan Heblich, and Holger Patzelt. 2012. Intergenerational transmission of entrepreneurial intentions. Journal of Business Venturing 27: 414-35. [CrossRef]

Maresch, Daniela, Rainer Harms, Norbert Kailer, and Birgit Wimmer-Wurm. 2016. The impact of entrepreneurship education on the entrepreneurial intention of students in science and engineering versus business studies university programs. Technological Forecasting and Social Change 104: 172-79. [CrossRef]

Martin, Bruce C., Jeffrey J. McNally, and Michael J. Kay. 2013. Examining the formation of human capital in entrepreneurship: A meta-analysis of entrepreneurship education outcomes. Journal of Business Venturing 28: 211-24. [CrossRef]

Mentoor, Etienne R., and Chris Friedrich. 2007. Is entrepreneurial education at South African universities successful? An empirical example. Industry and Higher Education 21: 221-32. [CrossRef]

Moberg, Kåre, Lene Vestergaard, Alain Fayolle, Dana Redford, Thomas Cooney, Slavica Singer, Klaus Sailer, and Diana Filip. 2014. How to Assess and Evaluate the Influence of Entrepreneurship Education: A Report of the ASTEE Project with a User Guide to the Tools. Odense: The Danish Foundation for Entrepreneurship-Young Enterprise.

Morris, Michael H., Justin W. Webb, Jun Fu, and Sujata Singhal. 2013. A competency-based perspective on entrepreneurship education: Conceptual and empirical insights. Journal of Small Business Management 51: 352-69. [CrossRef]

Musteen, Martina, Ross Curran, Nuno Arroteia, Maria Ripollés, and Andreu Blesa. 2018. A Community of Practice Approach to Teaching International Entrepreneurship. Administrative Sciences 8: 56. [CrossRef]

Nabi, Ghulam, Francisco Liñán, Alain Fayolle, Norris Krueger, and Andreas Walmsley. 2017. The impact of entrepreneurship education in higher education: A systematic review and research agenda. Academy of Management Learning \& Education 16: 277-99.

Nambisan, Satish. 2017. Digital entrepreneurship: Toward a digital technology perspective of entrepreneurship. Entrepreneurship Theory and Practice 41: 1029-55. [CrossRef]

O'Connor, Allan. 2013. A conceptual framework for entrepreneurship education policy: Meeting government and economic purposes. Journal of Business Venturing 28: 546-63. [CrossRef]

Oosterbeek, Hessel, Mirjam Van Praag, and Auke Ijsselstein. 2010. The impact of entrepreneurship education on entrepreneurship skills and motivation. European Economic Review 54: 442-54. [CrossRef]

Peterman, Nicole E., and Jessica Kennedy. 2003. Enterprise education: Influencing students' perceptions of entrepreneurship. Entrepreneurship Theory and Practice 28: 129-44. [CrossRef]

Pittaway, Luke, and Jason Cope. 2007. Simulating entrepreneurial learning: Integrating experiential and collaborative approaches to learning. Management Learning 38: 211-33. [CrossRef]

Pittaway, Luke, Elena Rodriguez-Falcon, Olaojo Aiyegbayo, and Amanda King. 2011. The role of entrepreneurship clubs and societies in entrepreneurial learning. International Small Business Journal 29: 37-57. [CrossRef] 
Pittaway, Luke, Jim Gazzard, Adam Shore, and Tom Williamson. 2015. Student clubs: Experiences in entrepreneurial learning. Entrepreneurship E Regional Development 27: 127-53.

Powers, Joshua B., and Patricia P. McDougall. 2005. University start-up formation and technology licensing with firms that go public: A resource-based view of academic entrepreneurship. Journal of Business Venturing 20: 291-311. [CrossRef]

Preedy, Sarah, and Paul Jones. 2017. Student-led enterprise groups and entrepreneurial learning: A UK perspective. Industry and Higher Education 31: 101-12. [CrossRef]

Rasmussen, Einar A., and Roger Sørheim. 2006. Action-based entrepreneurship education. Technovation 26: 185-94. [CrossRef]

Rauch, Andreas, and Willem Hulsink. 2015. Putting entrepreneurship education where the intention to act lies: An investigation into the impact of entrepreneurship education on entrepreneurial behaviour. Academy of Management Learning \& Education 14: 187-204.

Reynolds, Alison, and David Lewis. 2017. Teams Solve Problems Faster When They're More Cognitively Diverse. Harvrd Business Review 30. Available online: https:/ / hbr.org (accessed on 10 January 2019).

Rideout, Elaine C., and Denis O. Gray. 2013. Does entrepreneurship education really work? A review and methodological critique of the empirical literature on the effects of university-based entrepreneurship education. Journal of Small Business Management 51: 329-51. [CrossRef]

Rissola, Gabriel, Fernando Hervas, Milena Slavcheva, and Koen Jonkers. 2017. Place-Based Innovation Ecosystems: Espoo Innovation Garden and Aalto University (Finland). EUR 28545 EN. Brussels: European Union. [CrossRef]

Rousseau, Vincent, Caroline Aubé, and André Savoie. 2006. Teamwork Behaviors: A Review and an Integration of Frameworks. Small Group Research 37: 540-70. [CrossRef]

Salas, Eduardo, Dana E. Sims, and Shawn C. Burke. 2005. Is there a 'Big Five' in teamwork? Small Group Research 36: 555-99. [CrossRef]

Sánchez, José C. 2011. University training for entrepreneurial competencies: Its impact on intention of venture creation. International Entrepreneurship and Management Journal 7: 239-54. [CrossRef]

Sánchez, José C. 2013. The impact of an entrepreneurship education program on entrepreneurial competencies and intention. Journal of Small Business Management 51: 447-65. [CrossRef]

Sarasvathy, Saras D. 2003. Entrepreneurship as a science of the artificial. Journal of Economic Psychology 24: 203-20. [CrossRef]

Scherer, Robert F., Janet S. Adams, Susan S. Carley, and Frank A. Wiebe. 1989. Role model performance effects on development of entrepreneurial career preference. Entrepreneurship Theory and Practice 13: 53-72. [CrossRef]

Siegel, Donald S., and Mike Wright. 2015. Academic entrepreneurship: Time for a rethink? British Journal of Management 26: 582-95. [CrossRef]

Sieger, Philipp, Urs Fueglistaller, and Thomas Zellweger. 2014. Student Entrepreneurship across the Globe: A Look at Intentions and Activities. St. Gallen: Swiss Research Institute of Small Business and Entrepreneurship at the University of St. Gallen (KMU-HSG).

Sieger, Philipp, Urs Fueglistaller, and Thomas Zellweger. 2016. Student Entrepreneurship 2016: Insights From 50 Countries. St. Gallen and Bern: KMU-HSG/IMU.

Solomon, George. 2007. An examination of entrepreneurship education in the United States. Journal of Small Business and Enterprise Development 14: 168-82. [CrossRef]

Souitaris, Vangelis, Stefania Zerbinati, and Andreas Al-Laham. 2007. Do entrepreneurship programmes raise entrepreneurial intention of science and engineering students? The effect of learning, inspiration and resources. Journal of Business Venturing 22: 566-91. [CrossRef]

Stam, Erik. 2015. Entrepreneurial ecosystems and regional policy: A sympathetic critique. European Planning Studies 23: 1759-69. [CrossRef]

Thursby, Marie C., Anne W. Fuller, and Jerry Thursby. 2009. An integrated approach to educating professionals for careers in innovation. Academy of Management Learning and Education 8: 389-406.

Torrance, Wendy EF, Jonathan Rauch, William Aulet, Lenore Blum, Brad Burke, Troy D'Ambrosio, Kimberly de los Santos, Charles E. Eesley, William S. Green, Kenneth A. Harrington, and et al. 2013. Entrepreneurship Education Comes of Age on Campus: The Challenges and Rewards of Bringing Entrepreneurship to Higher Education. Available online: https:/ / papers.ssrn.com/sol3/papers.cfm?abstract_id=2307987 (accessed on 1 February 2019). 
Urbinati, Andrea, Davide Chiaroni, Vittorio Chiesa, and Federico Frattini. 2018. The role of digital technologies in open innovation processes: An exploratory multiple case study analysis. RED Management. [CrossRef]

Valerio, Alexandria, Brent Parton, and Alicia Robb. 2014. Entrepreneurship Education and Training Programs Around the World: Dimensions for Success. Washington: The World Bank.

Van Stel, André, Martin Carree, and Roy Thurik. 2005. The effect of entrepreneurial activity on national economic growth. Small Business Economics 24: 311-21. [CrossRef]

Vanevenhoven, Jeff, and Eric Liguori. 2013. The Impact of Entrepreneurship Education: Introducing the Entrepreneurship Education Project. Journal of Small Business Management 51: 315-28. [CrossRef]

Varano, Mirko, Elina Kähkönen, Hanna Aarnio, Maria Clavert, Matti Kaulio, Kent Thorén, Chrisje Haenen, Wim Van Petegem, Alessandra Colombelli, Giuliano Sansone, and et al. 2018. Entrepreneurship Education Ecosystems in Engineering and Technology (E4T). Paper presented at the SEFI Conference, Copenhagen, Denmark, September 17-21.

Viglialoro, Davide, and Paolo Landoni. 2019. Fostering social innovation through Social Incubators and Corporate Social Incubator: Evidence from Italy. Paper presented at the Designing Sustainability for All Conference, Milan, Italy, April 3-5.

Von Graevenitz, Georg, Dietmar Harhoff, and Richard Weber. 2010. The effects of entrepreneurship education. Journal of Economic Behavior \& Organization 76: 90-112.

Walter, Sascha G., Praveen K. Parboteeah, and Achim Walter. 2013. University Departments and Self-Employment Intentions of Business Students: A Cross-Level Analysis. Entrepreneurship Theory and Practice 37: 175-200. [CrossRef]

Wilson, Fiona, Jill Kickul, and Deborah Marlino. 2007. Gender entrepreneurial self-efficacy, and entrepreneurial career intentions: Implications for entrepreneurship education. Entrepreneurship Theory and Practice 31: 387-406. [CrossRef]

Zellweger, Thomas, Philipp Sieger, and Frank Halter. 2011. Should I stay or should I go? Career choice intentions of students with family business background. Journal of Business Venturing 26: 521-36. [CrossRef]

Zhang, Ying, Geert Duysters, and Myriam Cloodt. 2014. The role of entrepreneurship education as a predictor of university students' entrepreneurial intention. International Entrepreneurship and Management Journal 10: 623-41. [CrossRef]

(c) 2019 by the authors. Licensee MDPI, Basel, Switzerland. This article is an open access article distributed under the terms and conditions of the Creative Commons Attribution (CC BY) license (http://creativecommons.org/licenses/by/4.0/). 